G15(P) PAEDIATRICIANS' COMPETENCE AND ATTITUDES TOWARDS THEIR DIAGNOSTIC RADIOLOGY SKILLS

doi:10.1136/archdischild-2013-304107.028

M Sundaram, M Jawad, A Tabor. University Hospital of North Staffordshire, Stoke-onTrent, UK

Aims Many clinicians find themselves self-interpreting the radiological images of their patients, especially in the acute management setting whilst on-call. The aim of this study was to assess the competence and attitudes of paediatric clinicians towards their diagnostic radiology skills.

Methods We conducted a nine item self-administered questionnaire on 48 trainees and paediatricians. The domains of this questionnaire included previous formal training in diagnostic radiology at different stages of training, indication for self-taught radiology and satisfaction in current knowledge towards interpreting different types of radiology imaging. We also asked if there was an x-ray meeting in their department and whether there was a need for formal training in diagnostic radiology. Descriptive data were obtained. Results $39.6 \%(n=19)$ of our respondents were consultants and $41.7 \%(n=20)$ were registrars or associate specialists, all of which had a formal x-ray meeting in their current department. There was a significant difference between the number of respondents who attended a formal course in radiology interpretation, and those who were selftaught $(18.8 \%$ vs. $87.5 \% \mathrm{p}<0.001)$. However, nearly all respondents $(95.8 \%, n=46)$ felt there was a need for formal diagnostic radiology teaching, to be arranged either formally (58.7\%) or locally (41.3\%).

Conclusion The wide variation in methods, yet high prevalence of self-taught diagnostic radiology highlights a need for formal training, reinforced by the fact that nearly all respondents' feel formal teaching is necessary.

\section{G16(P) SUPPORTING TRAINEES RETURNING FROM MATERNITY LEAVE - ESTABLISHING A RETURN TO CLINICAL TRAINING COURSE}

doi:10.1136/archdischild-2013-304107.029

${ }^{1} \mathrm{~A}$ Brightwell, ${ }^{1} \mathrm{~S}$ Minson, ${ }^{2} \mathrm{~A}$ Ward, ${ }^{3} \mathrm{~A}$ Leigh, ${ }^{4} \mathrm{C}$ Fertleman. 'London School of Paediatrics, London Deanery, London, UK; ${ }^{2}$ Community Paediatrics, Camden PCT, London, UK: ${ }^{3}$ Paediatric Oncology, University College London Hospitals NHS Trust, London, UK; ${ }^{4}$ General Paediatrics, Whittington Health NHS Trust, London, UK

Background Time out of clinical practise is common in postgraduate paediatric training. Our Deanery can expect around 60 paediatric trainees to be on maternity leave at any time; the majority of whom choose to take the full year available to them.

There is limited evidence to describe how and when doctors' competence is lost during a period of absence from work, although a key factor appears to be how well the skills and knowledge were learned and practised before the career break. There is wide variability internationally and across speciality in the degree of support offered to doctors returning from a career break, and those schemes that do exist focus on doctors who have been absent from work for over two years Aim We developed, delivered and evaluated a one day return to clinical practise course for doctors in paediatric training.

Methods We invited all paediatric trainees who were on maternity leave to attend a free one-day return to clinical training course.

We developed a course to include recent updates in Paediatrics, low-fidelity simulation and discussion regarding anxieties around returning to work and strategies to maximise learning and training opportunities.

The course was facilitated by senior trainees who had recently returned to training from maternity leave as well as senior paediatricians who have successfully combined career and family life.

Results The course was attended by 22 trainees all of whom completed an evaluation.
The aspects of the course that trainees found most useful were networking, hot topics in paediatrics and simulation training. Many trainees felt that attending the course had helped them create an ongoing informal support network that would last beyond the single day of the course.

Conclusion Increasing numbers of junior doctors are taking time out of their training for maternity leave. No targeted educational support currently exists for this group.

We have demonstrated that a return to clinical practise course specifically targeting trainees on maternity leave was popular with participants all of whom stated that they had improved confidence and enthusiasm for returning to work.

\section{G17(P) AN OSCE IN SOMALILAND: MEDICAL ASSESSIMENT IN A RESOURCE POOR COUNTRY (RPC)}

doi:10.1136/archdischild-2013-304107.030

I Verber. Global Health, Tropical Health Educational Trust, London, UK

Aims To improve medical outcomes in a RPC by using improved assessments to drive up standards in learning.

Background Basic health indicators in Somaliland are among the worst in the world with high rates of maternal, newborn and child mortality and morbidity and poor immunisation coverage. There is a shortage of qualified healthcare professionals. This is exacerbated by Somaliland not being recognised internationally and therefore excluded from government aid. Hargeisa and Amoud Universities have established Faculties of Medicine with the aim of producing future doctors in Somaliland to address these healthcare issues.

Methods Five UK external examiners (including one paediatrician) travelled to Somaliland to work with the local faculty in implementing OSCE's to replace traditional clinical exams. Each examiner worked with local faculty in his own specialty in designing the exam and acted as lead examiner in his own subject but also as a station examiner in other subjects.

Outcomes Barriers to implementing the OSCE's were encountered. Somaliland has few experienced doctors many having fled the civil war. At Amoud University the most senior paediatrician had been qualified for 3 years. Very junior doctors had to be used as examiners and surrogates threatening the validity of the exam. Transport problems meant it was difficult to use out-patients as examination subjects and in-patients were generally too unwell Local faculty varied in their understanding of the principals of an OSCE some marking generically while others followed the mark scheme rigorously but without considering overall performance. Having to repeat each OSCE three times led to potential and actual breaches in security.

Nontheless an 8 station paediatric OSCE was delivered $(2$ clinical exam, 2 history, 2 counselling, and 2 unmanned data interpretation and management). The clinical exam and counselling stations demonstrated a good level of discrimination. Of 32 candidates in Hargesia 2 failed and 2 were borderline. Individual candidate's performance across the 5 OSCE's showed a high degree of concordance suggesting that the results were valid and reliable. Feedback from candidates was overwhelmingly positive.

Conclusions OSCE's are deliverable in RPC's. Ethical and professional behaviour needs reinforcing. Validating medical students' achievements will encourage further input from key stakeholders.

\section{G18(P) DEVELOPING STRONG LOCAL FACULTIES TO IMPROVE TEACHING FOR THE MRCPCH AND ENHANCE PAEDIATRIC TRAINING}

doi:10.1136/archdischild-2013-304107.031

'S Sukhani, 'M Menden, 1,2A Long, ${ }^{1,2} \mathrm{O}$ Mok, ' $\mathrm{J}$ Moreiras, 'R L'Heureux, ${ }^{2} \mathrm{~F}$ Cunnington. ${ }^{1}$ London Specialty School of Paediatrics, London Deanery, London, UK; 'Postgraduate Medical Education Department, Great Ormond Street Hospital, London, UK 
Background Pass rates for the Paediatric Clinical Membership exam (MRCPCH) vary across the UK1. This is equally true for London, where the availability of high quality exam-focused teaching differs significantly among hospitals 2 . Contributing factors include lack of familiarity with examination format, lack of time and/or faculty teaching expertise.

This disadvantages many trainees as repeated failures delay training progression. Some may be asked to leave the training programme. Method The London School of Paediatrics has developed a bespoke faculty development programme, RIPPLE, which aims to equip local trainers with skills to deliver high quality education, including exam-focused teaching.

The programme consists of an initial 3-day training course: day 1 focuses on enhancing teaching and facilitation skills. Day 2 aims to improve exam-focused teaching for the clinical MRCPCH. Day 3 provides trainers with coaching and mentoring skills to support trainees for the exam and in their workplace.

This was followed by an experiential component, including peerobserved learning, local Action Learning Sets and Regional sectorbased projects. The programme was accredited for CPD and mapped against the London Deanery Educational Supervisor Framework.

RIPPLE was delivered locally to address the needs of local trainers and to encourage networking in neighbouring Trusts.

Results The programme was well received in all 5 sectors across London, with 83 local trainers attending as delegates.

Pre- and post-course evaluation showed a dramatic increase in delegate confidence in delivering effective clinical MRCPCH teaching and supporting trainees with exam preparation. Delegates felt more confident in their ability to apply new teaching skills in various contexts and provide trainees with high quality feedback.

Following the course, delegates within every sector have successfully developed MRCPCH teaching programmes locally or as part of a regional programme. New teaching initiatives have also been instituted as result of the sector-based projects, which will further enhance postgraduate training in Paediatrics.

Conclusion This unique programme has equipped local faculty across London with skills to teach and support trainees through their MRCPCH exam. It also promotes integration of high quality teaching within daily clinical practise. Developing strong local faculties enhance local teaching quality and support trainees to achieve excellence in paediatric training.

\section{G19(P) A REGIONAL SURVEY OF PAEDIATRIC TRAINEES ABOUT AIRWAY MANAGEMENT SKILLS}

doi:10.1136/archdischild-2013-304107.032

A Shenvi, L Johansen, RH Mupanemunda. Neonatal Medicine, Birmingham Heartlands Hospital, Birmingham, UK

Background Postgraduate training in paediatrics has moved from time based to competency based learning. Due to the current full shift pattern of working, opportunities available to the individual trainee will vary greatly. One of the critical core competencies expected of all paediatric trainees is the management of the neonatal airway including a difficult airway. Despite this, there is no specific airway management syllabus in the neonatal curriculum published by the RCPCH and no formal focussed training programme for trainees to achieve this competency.

Aim To ascertain the competence of paediatric trainees at neonatal airway management.

Methods A regional questionnaire survey of paediatric registrars on the middle grade rota between May-Oct 2012

Results A total of 111 paediatric registrars at various stages of training answered the survey. $80 \%$ of trainees were NLS providers while $73 \%$ were APLS providers. Nearly half had received formal in-service training including theoretical and practical sessions on airway management while $23 \%$ trainees had received some formal training in anaesthetics. $41 \%$ trainees at ST4-5 level and 5\% trainees at ST6-ST8 level had performed less than 20 intubations. 32\% trainees had used advanced airway adjuncts ie. laryngeal mask airway (LMA) during training. While majority had used a manikin model to practise neonatal airway management techniques, some had experienced high fidelity simulation and only a handful had the experience of other methods such as e-learning, multimedia, closed circuit television or video laryngoscope. $80 \%$ trainees strongly felt a structured training programme would be valuable to them, particularly at an early stage of training.

Conclusion Training on neonatal airway management skills is not uniform amongst paediatric trainees. A reduction in training time may result in some trainees failing to achieve basic neonatal airway competencies. Successful completion of life support courses ie, NLS and APLS does not confer mastery in airway management skills. Major changes have to take place in the way training is delivered if quality is to be maintained. A structured programme using a variety of technology enhanced teaching methods including high fidelity simulation is required at commencement of registrar training. This will ensure that future trainees achieve competence in this vital skill.

\section{G20(P) PAEDIATRICIANS' AND GPS' UNDERSTANDING OF THE "MEDICINE NOT-LICENCED FOR USE IN CHILDREN"}

doi:10.1136/archdischild-2013-304107.033

M Baba. Paediatrics, Cardiff and Vale UHB, Cardiff, UK

Background Marketing authorization (MA), previously known as product licence, is what is referred to when talking about "medicines not-licenced for use in children". Medicines Act and the $\mathrm{RCPCH} / \mathrm{NPPG}$ policy statement support and give guidance on use of such drugs, which is about $75 \%$ of prescribing in Paediatrics. Their use is even more in sub-specialties, creating much anxiety in GPs who are asked to prescribe. Increasingly, the hospital pharmacy is dispensing these "specialist drugs" that have been refused dispensation in the community, often due to misunderstanding about MA.

Aim To investigate the understanding of the term "not-licenced for use in children" by GPs and Paediatricians.

Methods A questionnaire with a multiple choice question asking what "not-licenced for use in children" means was administered at various meetings for GPs and Paediatricians over a two-week period. The choice of answers were; "Illegal to supply for children's use", "Illegal to prescribe for children", "Safety in children untested", "Efficacy in children untested", "Not to be marketed for children's use" and "Pharmacists require special authorisation by prescriber". Respondents chose as many answers as they thought applicable.

Results There were 80 respondents; 46 Paediatricians (14 consultants and 32 trainees), 29 GPs (15 prescribing leads and 14 trainees) and 5 Foundation Year doctors.

Overall, "Safety untested" was the most frequent answer (61\%) followed by "Not to be marketed" $(58 \%)$, and "Efficacy untested" (48\%). 8(10\%) trainees thought supplying unlicensed drugs was illegal and $7(6$ trainees, 1 consultant $(9 \%))$ thought it was illegal to prescribe.

More consultants knew that "licence" means marketing authorisation(86\%) while about a half(47\%) of the GP prescribing leads did. (Graph1) However, more GPs chose purely correct answer i.e. "not for marketing" (33\%), followed by consultants (29\%). The absence of safety and efficacy testing in children may have been true for drugs developed before 2007 when the Paediatric Regulations came into force. Allowing for this $58 \%$ of consultants and $46 \%$ of qualified GPs gave the correct combination of answers. 